\title{
A Rapid and Inexpensive Technique for Assessing the Reinforcing Effects of Opiate Drugs ${ }^{1}$
}

\author{
R. J. KATZ AND GLEN GORMEZANO \\ Mental Health Research Institute, Department of Psychiatry, University of Michigan Medical Center, Ann \\ Arbor, MI 48109
}

Received 19 June 1978

\begin{abstract}
KATZ, R. J. AND G. GORMEZANO. A rapid and inexpensive technique for assessing the reinforcing effects of opiate drugs. PHARMAC. BIOCHEM. BEHAV. 11(2) 231-233, 1979.-Adult male Sprague-Dawley rats were placed in an apparatus consisting of 2 distinctive interconnected chambers. Choice preferences developed and stabilized over three 30 min exposures. Central injection of morphine or an enkephalin analogue in conjunction with placement upon the nonpreferred side caused a preference shift which was not evident in control subjects. Classical conditioning of opiate effects to distinctive environments may offer a novel means of assessing the hedonic effects of these compounds.
\end{abstract}

Classical conditioning D-Ala ${ }^{2}$ Leu-Enkephalinamide Morphine Opiate Reinforcement

TRADITIONALLY, two methods have been available to pharmacologists wishing to investigate the reinforcing effects of drugs. One method is self-administration $[4,10,11]$, in which animals perform an operant task to produce a contingent central or peripheral drug infusion. The second method involves altering ongoing patterns of intracranial self stimulation (e.g., rate or threshold) $[1,7,10]$. Other, although less commonly employed, techniques involve the establishment of secondary (i.e., conditioned) reinforcement to stimuli paired with drugs and subsequent operant testing [4].

These procedures are highly effective but generally involve costly systems for programming contingencies and drug delivery. Moreover, often considerable experimenter time is necessary for behavioral shaping. We have developed a simplified behavioral procedure for assessing the motivating properties of drugs based upon classical conditioning. The present report demonstrates this technique using 2 opiate agonists, a long-lasting analogue of leu-enkephalin and morphine.

\section{METHOD}

\section{Animals}

Fifty-nine adult male Sprague-Dawley rats $(250-380 \mathrm{~g} / \mathrm{rat}$; Charles River Farms, Portage, MI) were individually maintained upon ad lib diets of laboratory chow (Teklad $4.0 \%$ fat diet, S-0836; Madison, WI) and tap water. Lighting cycles of
$12 \mathrm{hr}$ (lights on=8:00-20:00 hr) were automatically programmed.

\section{Apparatus}

The testing apparatus consisted of 2 highly distinctive interconnected chambers. One chamber was white, cubical (18 $\mathrm{cm} /$ side) and had a grid floor. The other was black, prismatic $(18 \mathrm{~cm}$ height $)$ with an isosceles triangular base $(18 \times 18 \times 25.4$ $\mathrm{cm}$ ) and a mesh floor. A $9.5 \times 9.5 \mathrm{~cm}$ aperture with a sliding door connected the sides. The box is presented visually as Fig. 1. Data were recorded based on visual observation and a manually operated timer.

\section{Cannula Construction and Implantation}

All animals $(n=32)$ used for the evaluation of the enkephalin analog were anesthetized with sodium pentobarbital (Nembutal $35 \mathrm{mg} / \mathrm{kg}$ ) and stereotaxically implanted with a commercially prepared 23 ga cannula (Plastic Products, C313). A minimum of 7 days recovery preceded testing. At the close of all tests, subjects were injected with $10 \mu \mathrm{l}$ of commercial black ink and decapitated within $10 \mathrm{~min}$. Brains were removed and dissected, and the ventricles exposed. Only animals with ink through the entire ventricular system were included in the experimental group. Experimental animals $(n=4)$ showing no or partial ink diffusion were included

\footnotetext{
'All correspondence to first author. This project was supported in part by postdoctoral Grant MH-07417 from the National Institute of Mental Health, through the Mental Health Research Institute, and was carried out by the second author in partial fulfillment of the requirements for an undergraduate honors thesis in Biology at the University of Michigan. We are grateful to Cindy Reynolds and Esther Washington for editorial assistance.
} 


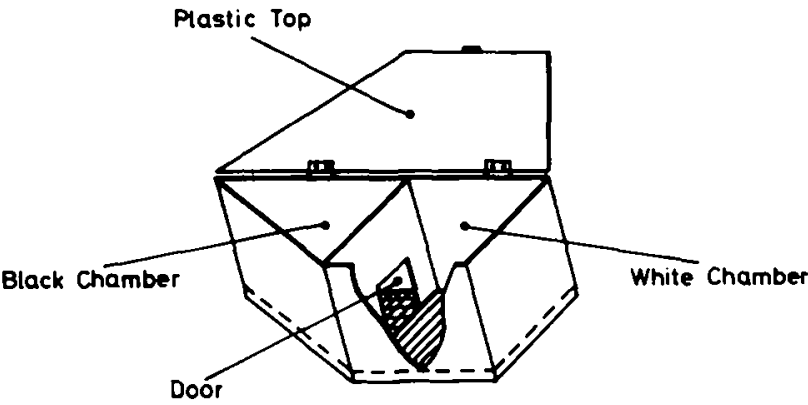

FIG. 1. Experimental apparatus for drug evaluation. A detailed description of the box is provided in text.

in control one. Animals for the evaluation of morphine $(n=27)$ were not implanted.

\section{Behavioral Procedure}

Animals were placed in the apparatus with initial side placement counterbalanced across subjects and sessions. All sessions were $30 \mathrm{~min}$ and were separated by a minimum of 24 hr. Over this time, side preference developed and stabilized. For 55 of 59 animals, the black side was preferred. The fourth session was a conditioning session. Experimental animals $(n=12)$ were placed in the nonpreferred side and 10 min later were injected with a low dose of enkephalin analogue (25 $\mu \mathrm{g}$ of D-Ala ${ }^{2}$ leu-enkephalinamide; Peninsula 8619, San Carlos, CA) in a vehicle of $10 \mu \mathrm{l} 0.9 \%$ sodium chloride). During this period access to the second chamber was prevented by a removable door (Fig. 1). Following the injection subjects were returned to the apparatus for the remaining $20 \mathrm{~min}$. The fifth session involved free choice and assessment of altered side preference. Again initial placement was counterbalanced across animals and conditions.

Injections for the enkephalin experiment were through a permanently indwelling cannula aimed at the lateral ventricle, and involved an infusion time of $30 \mathrm{sec}$ or less using a Hamilton microsyringe. Morphine injections $(1.0 \mathrm{mg} / \mathrm{kg}$ morphine sulfate) were intraperitoneal. Two control groups were included for both experiments. Control one $(n=10,9$, respectively, for the enkephalin analog and morphine) received identical treatment but was injected with vehicle alone. Control two ( $n=10,9$, respectively) received drug injections in their home cages. Control one allowed the evaluation of nonspecific effects of both environmental and procedural habituation while control two assessed drug sensitization effects [9].

\section{Analysis}

Statistical analysis was by repeated measures analysis of variance supplemented by individual $t$-tests [5]. Results are presented in Tables 1 and 2 . All results are mean \pm standard error.

For the enkephalin groups (Table 1) ANOVA indicated significant effects of groups, $\mathrm{F}(2,29)=4.0, p<0.05$, trials, $\mathrm{F}(1,29)=31.6, \quad p<0.001$, and interaction, $\mathrm{F}(1,29)=12.8$, $p<0.001$. It is clear from examination of Table 1 that these changes are due to reduced preference in the experimental group while the control groups remained unchanged. An essentially similar pattern emerged for the morphine group (Table 2) with conditioning of preference restricted to the experimental group (F ratios for groups, trials, and interaction,
TABLE 1

EFFECTS OF AN ENKEPHALIN ANALOGUE UPON SPONTANEOUS CHOICE PATTERNS (MEAN \pm STANDARD ERROR)

\begin{tabular}{lcrr}
\hline Group & Experimental & Control one & Control two \\
\hline $\begin{array}{l}\text { Time on } \\
\text { preferred side }\end{array}$ & & & \\
pre-injection & $24.2 \pm 1.9$ & $26.9 \pm 0.9$ & $21.5 \pm 2.6$ \\
$\begin{array}{l}\text { Time on } \\
\text { preferred side } \\
\text { post-injection }\end{array}$ & $13.4 \pm 3.5$ & $27.3 \pm 1.0$ & $23.0 \pm 1.7$ \\
$t=$ & $2.7^{*}$ & 0.3 & 0.5 \\
\hline
\end{tabular}

${ }^{*} p<0.05 t$-test for related measures.

TABLE 2

EFFECTS OF MORPHINE UPON SPONTANEOUS CHOICE PATTERNS (MEAN \pm STANDARD ERROR)

\begin{tabular}{llll}
\hline Group & Experimental & Control one & Control two \\
\hline
\end{tabular}

Time on

Preferred side

pre-injection

$26.6 \pm 1.4$

$24.6 \pm 2.3$

$25.4 \pm 0.8$

Time on

preferred side

post-injection

\begin{tabular}{rrr}
$22.1 \pm 0.9$ & $22.8 \pm 0.2$ & $24.1 \pm 1.8$ \\
$2.5^{*}$ & 0.3 & 0.1 \\
\hline
\end{tabular}

$t=$

ches.

${ }^{*} p<0.05$ t-test for related measures.

respectively, were $F(2,24)=0.4 ; \quad F(1,24)=27.0 ; \quad F(1,24=$ $20.2 ; p>0.05,<0.05<0.05$, respectively). The absence of a group effect contrasts with the enkephalin results.

\section{DISCUSSION}

We classically conditioned the hedonic effects of opiates to an experimental environment, and evaluated this change through alterations in preference. While our design bears superficial resemblance to an operant secondary reinforcement design [4], it should be noted that no novel behaviors were involved in testing, nor were any instrumental responses shaped. The present design also bears some similarity to an earlier learning paradigm of Beach [2]. Our results are consistent with this earlier finding, as well as to a recent related experiment utilizing psychostimulant drugs [8]. It must be noted the effect with morphine was of a relatively small magnitude, and not evident in a group effect per se.

The present design utilized normal and unconditioned environmental approach and preference patterns which have long been recognized as inherent in classical conditioning $[12,13]$. Clearly, whatever conceptualization is used, and this remains a procedural matter [3], our results suggest a simple means of evaluating the hedonic effects of opiates and possibly other classes of drugs. Since the present design used a box of simple and inexpensive construction and short term (i.e., $150 \mathrm{~min} / \mathrm{animal}$ ) visual observation, we feel this method is time and cost effective. This method may therefore have considerable utility in assessing other new compounds. 


\section{REFERENCES}

1. Adams, R. J., S. A. Lorens and C. L. Mitchell. Morphine enhances lateral hypothalamic self stimulation in the rat. Proc. Soc. exp. Biol. 140: 770-771, 1972.

2. Beach, H. D. Morphine addiction in rats. Can. J. Psychol. 11: 104-112, 1957.

3. Bitterman, M. E. Techniques for the study of learning in animals. Psychol. Bull. 59: 81-93, 1962.

4. Davis, W. M. and S. G. Smith. Behavioral control exerted by Amphetamine based conditioned reinforcer. In: Drug Addiction, Vol. 3, edited by J. M. Singh and H. Lal. Miami: Symposia Specialists, 1974, pp. 209-219.

5. Dixon, W. J. and F. J. Massey. Introduction to Statistical Analysis. New York: McGraw-Hill, 1969.

6. Gamzu, E. and E. Schwam. Autoshaping and automaintenance of a key press response in squirrel monkeys. J. exp. Analysis Behav. 21: 361-371, 1974.

7. Marcus, R. and C. Kornetsky. Negative and positive intracranial reinforcement thresholds-effects of morphine. Psychopharmacologia 38: 1-13, 1974.
8. Reicher, M. A. and E. W. Holman. Location preference and flavor aversion reinforced by amphetamine in rats. Anim. Learn. Behav. 5: 343-346, 1977.

9. Rescorla, R. Pavlovian conditioning and its proper control procedures. Psychol. Rev. 74: 71-80, 1967.

10. Stein, L. Reward transmitters: Catecholamines and opioid peptides. In: Psychopharmacology, A Generation of Progress, edited by M. A. Lipton, A. DiMascio and K. F. Killam. New York: Raven Press, 1978, pp. 569-581.

11. Weeks, J. R. Environmental influences affecting the voluntary intake of drugs: an overview. In: Behavioral Pharmacology, The Current Status, edited by B. Weiss and V. G. Laties. New York: Plenum, 1976, pp. 3-11.

12. Woodruff, G. and D. R. Williams. The associative relation underlying autoshaping in the pigeon. J. exp. Analysis Behav. 26: $1-13,1976$.

13. Zener, $K$. The significance of behavior accompanying conditioned salivary secretion for theories of the conditioned response. Am. J. Psychol. 50: 384-403, 1937. 